\title{
A Class 1 Hemoglobin Gene from Alnus firma Functions in Symbiotic and Nonsymbiotic Tissues to Detoxify Nitric Oxide
}

\author{
Fuyuko Sasakura, ${ }^{1}$ Toshiki Uchiumi, ${ }^{2}$ Yoshikazu Shimoda, ${ }^{3}$ Akihiro Suzuki, ${ }^{4}$ Katsumi Takenouchi, ${ }^{1}$ \\ Shiro Higashi, ${ }^{2}$ and Mikiko $\mathrm{Abe}^{2}$ \\ ${ }^{1}$ Graduate School of Science and Technology, Kagoshima University, Kagoshima 890-0065, Japan; ${ }^{2}$ Department \\ of Chemistry and Bioscience, Faculty of Science, Kagoshima University, Kagoshima 890-0065, Japan; ${ }^{3}$ Kazusa DNA \\ Research Institute, Chiba 292-0812, Japan; ${ }^{4}$ Department of Agricultural Sciences, Faculty of Agriculture, Saga University, \\ Saga 840-8502, Japan
}

Submitted 25 July 2005. Accepted 22 November 2005.

\begin{abstract}
Actinorhizal symbiosis is as important in biological nitrogen fixation as legume-rhizobium symbiosis in the global nitrogen cycle. To understand the function of hemoglobin (Hb) in actinorhizal symbiosis, we characterized a $\mathbf{H b}$ of Alnus firma, AfHb1. A cDNA that encodes nonsymbiotic Hb (nonsym-Hb) was isolated from a cDNA library of $A$. firma nodules probed with $\mathrm{LjHb1}$, a nonsym-Hb of Lotus japonicus. No homolog of symbiotic Hb (sym-Hb) could be identified by screening in the cDNA library or by polymerase chain reaction (PCR) using degenerate primers for other sym-Hb genes. The deduced amino acid sequence of AfHb1 showed $92 \%$ sequence similarity with a class 1 nonsym-Hb of Casuarina glauca. Quantitative reverse transcriptase-PCR analysis showed that $A f H b 1$ was expressed strongly in the nodules and enhanced expression was detected under cold stress but not under hypoxia or osmotic stress. Moreover, $A f H b 1$ was strongly induced by the application of nitric oxide (NO) donors, and the application of a NO scavenger suppressed the effect of NO donors. Acetylene reduction was strongly inhibited by the addition of NO donors. AfHb1 may support the nitrogen fixation ability of members of the genus Frankia as a NO scavenger.
\end{abstract}

Additional keyword: actinorhizal plant.

Actinorhizal plants belong to eight families and 25 genera of angiosperms and have the symbiotic ability to form nitrogenfixing nodules with actinomycetes of the genus Frankia. The host species of Frankia strains are mostly woody plants. These plants are ecologically important in reforestation and environmental restoration. The symbiosis between rhizobia and legumes has been studied extensively, but the details of actinorhizal symbioses are less well understood. The isolation of AgNOD-CP (nodule-specific cysteine proteinase) of Alnus glutinosa was reported (Goetting-Minesky et al. 1994) as the first isolation of an actinorhizal nodulin gene. Since then, putative symbiotic genes have been identified from other ac-

Corresponding author: Mikiko Abe; Korimoto 1-21-35, Kagoshima City, Kagoshima 890-0065, Japan; Telephone: +81-99-285-8165; Fax: +81-99285-8163; E-mail: mikiabe@ sci.kagoshima-u.ac.jp

Nucleotide sequence data for $A f H b 1$ is available from the DDBJ database under accession number AB221344. tinorhizal species, including symbiotic $\mathrm{Hb}$ (sym-Hb) genes expressed only in root nodules of Casuarina glauca (JacobsenLyon et al. 1995).

Plant hemoglobins $(\mathrm{Hb})$ have been identified in various species of legumes, nonlegumes, and actinorhizal plants (e.g., $C$. glauca, Myrica gale, A. glutinosa), so $\mathrm{Hb}$ are believed to exist widely in the plant kingdom. There are at least three distinct types of plant $\mathrm{Hb}$, symbiotic, nonsymbiotic, and truncated.

Sym-Hb (a subgroup of class $2 \mathrm{Hb}$, [Guldner et al. 2004]), the most well-known plant $\mathrm{Hb}$, are designated as leghemoglobins in legumes and are found mainly in nodules of plants capable of symbiotic nitrogen fixation. Their function in nodules is to regulate oxygen concentration in parallel with oxygen supply to the nitrogen-fixing symbiont (Appleby 1992).

Nonsym-Hb have been identified in many dicots, monocots, and nonvascular plants (Hunt et al. 2001). According to their phylogeny, biochemical characteristics, and profiles of gene expression, they are classified into two distinct groups, class 1 and class $2 \mathrm{Hb}$. While the functions of the two classes are not yet fully understood, their profiles of gene expression suggest that their functions are different from each other. Class $1 \mathrm{Hb}$ exhibit an extremely high affinity for oxygen (Arrendondo-Peter et al. 1997; Duff et al. 1997; Trevaskis et al. 1997) and nitric oxide (NO) (Dordas et al. 2004; Perazzolli et al. 2004). Seregélyes and associates (2000) reported that Mhbl, a class $1 \mathrm{Hb}$ gene of alfalfa (Medicago sativa), has a potential link to the NO signaling pathway because both Mhbl and NO synthase are localized in the nucleolus. Furthermore, the involvement of class $1 \mathrm{Hb}$ in hypoxic stress has been discussed in many reports (Taylor et al. 1994). Dordas and associates (2004) reported that NO was produced in maize cell-suspension culture via nitrate reductase during hypoxia and class $1 \mathrm{Hb}$ have a significant function in regulating NO levels. These reports and other studies of transgenic Arabidopsis (Hunt et al. 2002) and alfalfa root cultures (Dordas et al. 2003) overexpressing class $1 \mathrm{Hb}$ genes suggest that class $1 \mathrm{Hb}$ may be involved in NO-mediated pathways of hypoxic or early-growth states. A class $2 \mathrm{Hb}$ isolated from Arabidopsis thaliana, AHB2, has high similarity to sym-Hb in sequence and oxygen-binding properties and is induced by cold (Trevaskis et al. 1997). Treatment with cytokinins, a class of phytohormones that can induce a large number of different nodulin genes (Jiménez-Zurdo et al. 2000; Mathesius et al. 2000), also induced the expression of $A H B 2$ (Hunt et al. 2001). Additionally, class $2 \mathrm{Hb}$ genes of tomato (Lycopersi- 
con esculentum) were isolated from disease- and multiple elicitor-induced cDNA library and cDNA library of a Pseudomonas-resistant cultivar (Hunt et al. 2001). These results let us speculate that class $2 \mathrm{Hb}$ are involved in interactions with microorganisms.

Truncated $\mathrm{Hb}$ that exhibit an aberrant tertiary structure based on a 2-on-2 $\alpha$-helical sandwich have been found. They are widely distributed in bacteria, unicellular eukaryotes, and plants, and share some characteristics with nonsymbiotic $\mathrm{Hb}$ (nonsym-Hb) (Watts et al. 2001). Plant-truncated $\mathrm{Hb}$ were not induced by hypoxia or treatment with phytohormones (Vieweg et al. 2005), and the role of these genes in plants is unknown so far.

Among actinorhizal plants, $\mathrm{Hb}$ proteins have been isolated from C. glauca (Fleming et al. 1987), M. gale (Pathirana and Tjepkema 1995), and A. glutinosa (Suharjo and Tjepkema 1995). Both the sym- and the nonsym-Hb from $C$. glauca have been sequenced, and their types have been determined (Guldner et al. 2004), but types of Hb proteins from M. gale and $A$. glutinosa have not been determined. Genus Casuarina is unique among actinorhizal plants; the symbiotic genus Frankia strains do not form vesicles within Casuarina nodules (Berg and McDowell 1987), but it does form vesicles when grown in culture media (Murry et al. 1985). In Alnus nodules, spherical vesicles are formed. Each vesicle is surrounded by a multilayered lipid envelope, which presumably functions as an oxygen diffusion barrier (Parsons et al. 1987). These morphological differences between Casuarina nodules and Alnus nodules suggest different roles of $\mathrm{Hb}$ in actinorhizal symbiosis. To reveal the role of Alnus firma $\mathrm{Hb}$, we characterized a nonsym-Hb gene, $A f H b 1$, and explored putative roles of $A f H b l$ in plants and root nodules in relation to NO. Our results will help in understanding the role of nonsym-Hb in Alnus-Frankia symbiosis.

\section{RESULTS}

Morphology of $A$. firma root nodules.

Root nodules of $A$. firma have a central vascular bundle and an apical meristem (Fig. 1A). In actinorhizal nodules, including those in the apical meristem, there are four zones of cortical cells (Ribeiro et al. 1995). In the infection (prefixation) zone, we observed a number of small, young vesicles formed by Frankia strains (Fig. 1B). The orientation and shape of vesicles vary among host plant genera (Huss-Danell 1997) and have been well observed in Alnus species. The cells in the nitrogen fixation zone were mature and spherical (Fig. 1C). Vesicles of Frankia root nodules were degraded in the cells of the senescence zone (Fig. 1D). The symbiotic Frankia root nodule produced a lipid envelope exterior to the cell wall of the vesicle, and incomplete septa were present in the vesicle (Fig. 1E).

\section{Identification and sequence \\ of the $\mathrm{Hb}$ gene of $A$. firma.}

We constructed a cDNA library from nitrogen-fixing nodules of A. firma. After the ligated products were packaged into phage particles, the number of independent clones in the cDNA library was approximately $1 \times 10^{8}$ plaque-forming units (PFU) per milliliter. By screening the cDNA library, we isolated nine positive clones homologous to an $L$. japonicus nonsym-Hb gene, $\mathrm{LjHbl}$ (accession number AB238220). We also performed genomic Southern hybridization using sym-Hb genes of $C$. glauca (accession number L28826) and L. japonicus, LjLb3 (accession number AB238219) as probes. Hybridization using a C. glauca sym-Hb probe showed no signal in spite of lowstringent washing conditions, and hybridization using $L j L b 3$ probe showed two bands in each BamHI- and EcoRI-digested lane (data not shown). However, no positive clones homologous to a sym-Hb $L j L b 3$ were detected in the cDNA library,
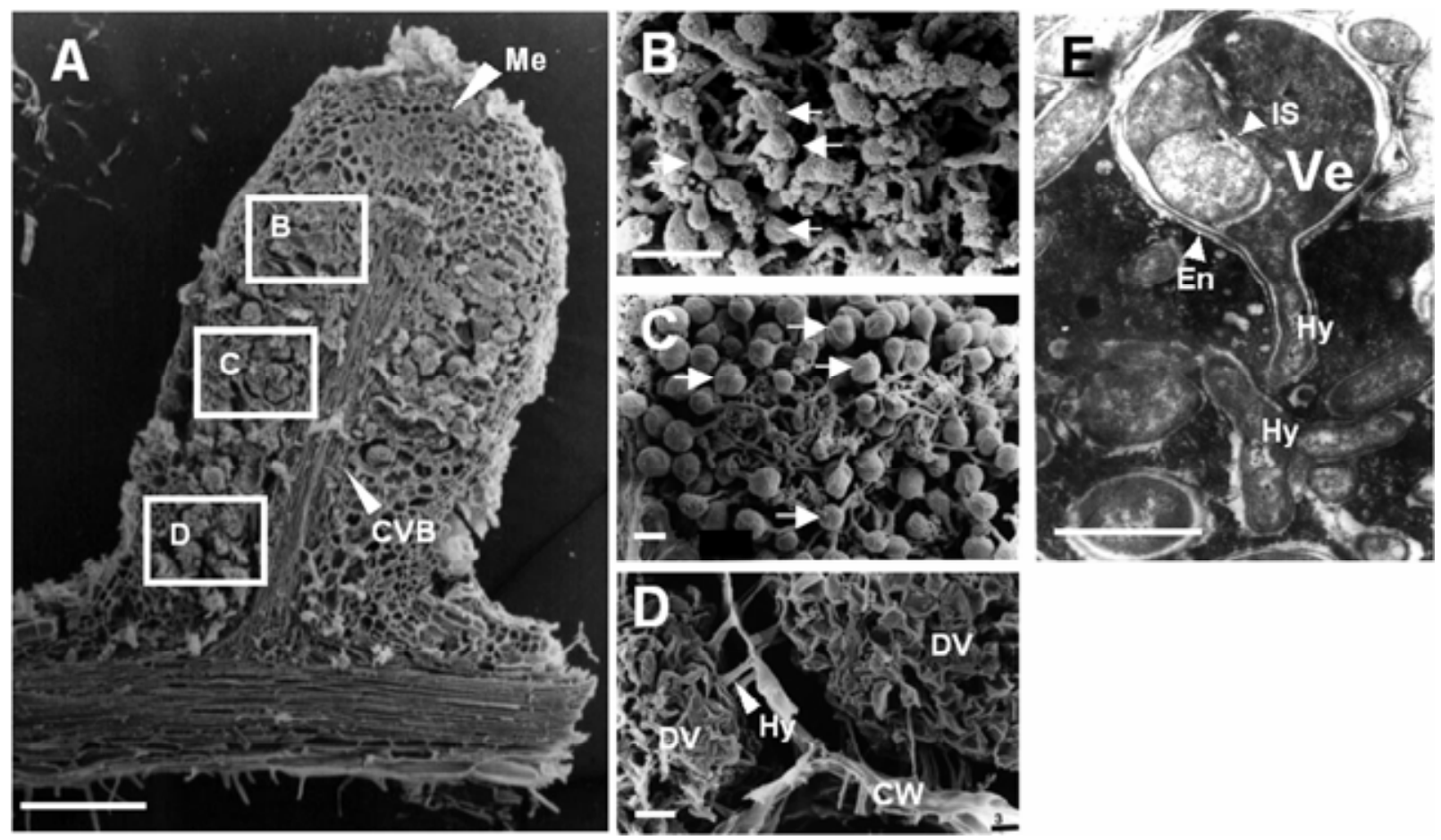

Fig. 1. Scanning and transmission electron micrographs of Alnus firma root nodules. A, Longitudinal section of root nodule containing a central vascular bundle (CVB) and apical meristem (Me). B, High magnification of area 'B' in A. A number of small, young vesicles formed by Frankia spp. (arrows) are seen in the infection (prefixation) zone. C, High magnification of area ' $\mathrm{C}$ ' in $\mathrm{A}$. The nitrogen fixation zone is filled with mature vesicles (arrows), allowing nitrogen fixation. D, High magnification of area 'D' in A. In the senescence zone, Frankia vesicles are degraded in infected cells. E, Cross-section of vesicle of root nodule. A lipid envelope (En) is present exterior to the cell wall of the vesicle, and incomplete septa (IS) are present in the vesicle. DV = degraded vesicle, $\mathrm{Hy}=$ Frankia hypha, $\mathrm{CW}=$ cell wall, and $\mathrm{Ve}=$ vesicle. Bars indicate $200 \mu \mathrm{m}(\mathrm{A}), 5 \mu \mathrm{m}(\mathrm{B}, \mathrm{C}, \mathrm{D})$, and $3 \mu \mathrm{m}(\mathrm{E})$. 
even though we constructed the library from fully developed nitrogen-fixing nodules. Furthermore, no fragments of sym-Hb gene homologs could be amplified by polymerase chain reaction (PCR) using the degenerate primers designed from highly conserved regions of several sym-Hb.

Sequence analysis identified one $\mathrm{Hb}$ gene out of the nine positive clones, which we named $A f H b 1$. AfHbl showed 88 and $79 \%$ homology in cDNA with nonsym-Hb genes of $C$. glauca (an actinorhizal plant) and L. japonicus, respectively. A genomic DNA fragment (592 bp) of AfHbl was amplified by PCR with primer pair AfHb-FF1/AfHb1-R3, designed from the cDNA sequence. The genomic sequence showed that AfHbl consists of four exons spliced by three introns at positions identical to those in known plant $\mathrm{Hb}$ genes (Fig. 2A). Genomic Southern hybridization probing with AfHbl (amplified by primer pair AfHb-FF1/AfHb-RR) showed one or three hybridization bands in each lane. There exist two HindIII sites and no EcoRI or PstI sites, so $A f H b l$ might exist as a single copy in the genome of $A$. firma (Fig. 3). The sequence of the $5^{\prime}$ upstream region of $A f H b l$ was determined by thermal asymmetric interlaced (TAIL)-PCR (Liu and Whittier 1995). The proximal region of the $A f H b 1$ promoter contains two important nodulin motif sequences that are highly conserved in sym-Hb genes of legumes (Andersson et al. 1996); motifs AAAGAT and CTCTT are conserved in the promoters of sym-Hb of legumes such as L. japonicus ( $L j L b 1, L j L b 2, L j L b 3)$, soybean (Lbc1, Lbc2, Lbc3, and Lba), Sesbania rostrata (Srglb3), and Medicago truncatula (MtLb1, MtLb2) and in a nonsym-Hb of Parasponia andersonii (Fig. 2B). In addition, another motif (GAAGAG) that exists typically in the promoter of nonsym-
$\mathrm{Hb}$ and is not conserved in sym-Hb of legumes (Andersson et al. 1996; Uchiumi et al. 2002) is also conserved in the $A f H b l$ promoter just downstream of the AAAGAT and CTCTT motifs (Fig. 2B). To investigate whether these motifs are conserved among other plant $\mathrm{Hb}$ genes, we compared the sequences of $\mathrm{Hb}$ gene promoters of the nonnodulating plants Arabidopsis thaliana and Oryza sativa (Fig. 2B). We found two motifs (AAAGAT and CTCTT) also conserved in all promoters investigated at similar sites as in the $A f H b l$ promoter, but the spacing between the two motifs varies in each promoter (Fig. 2B).

\section{Phylogeny of AfHb1.}

The deduced amino acid sequence of AfHb1 shows 92\% sequence similarity with the nonsym-Hb of $C$. glauca. AfHb1 conserves several residues involved in heme- and ligand-binding domains - the proximal and distal His, Phe, and Pro-which are conserved in known plant $\mathrm{Hb}$ (data not shown). We constructed a phylogenetic tree based on deduced amino acid sequences with other plant $\mathrm{Hb}$ by the neighbor-joining method, using ClustalW. AfHb1 was classified in a branch distant from sym-Hb of legumes, in the cluster of class 1 nonsym-Hb (Fig. 4). AfHb1 is located closely to the nonsym- $\mathrm{Hb}$ of the actinorhizal plant C. glauca.

\section{Expression of $\boldsymbol{A f H b 1}$ in different tissues.}

The expression of $A f H b l$ in leaves, stems, roots, and nodules of $A$. firma was estimated by quantitative reverse transcriptase (RT)-PCR (Fig. 5A). The expression level of AfHbl was significantly enhanced in nodules, up to 300 times that in other organs (Fig. 5A). The Casuarina nonsym-Hb gene was ex-

A

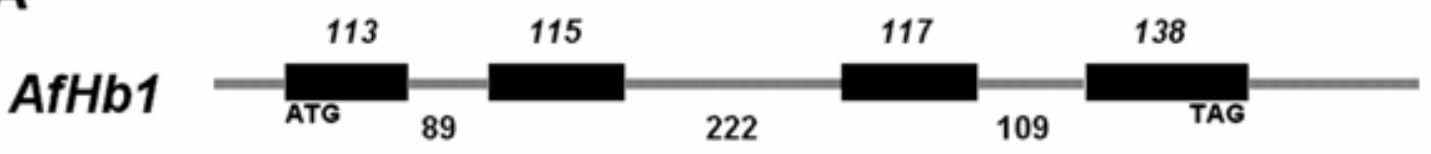

B

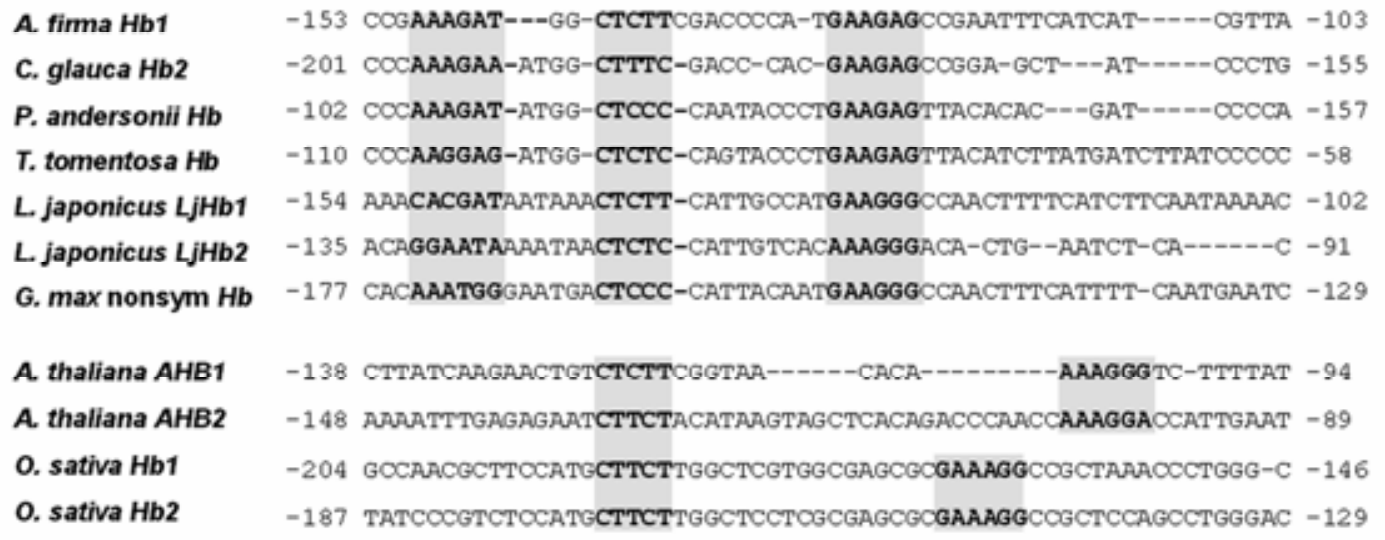

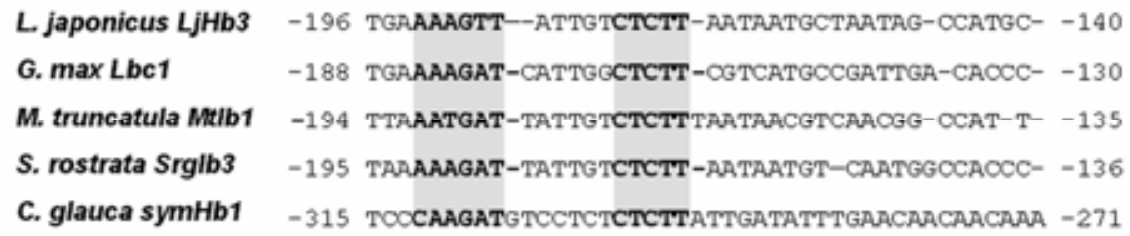

Fig. 2. Characteristics of the genomic sequence of $A f H b 1$. A, Structure of genomic $A f H b 1$. Boxes indicate exons, lines indicate introns. Numbers indicate the sizes of exons and introns in basepairs. B, Alignment of promoter regions of AfHbl (upper block), nonsymbiotic hemoglobin (nonsym-Hb) genes (middle), and symbiotic $\mathrm{Hb}$ genes (lower). All sequences are numbered from the translation initiation codon ATG. Two motifs (CTCTT and GAAGAG) are conserved in the promoters of $A f H b 1$ and other nonsym $\mathrm{Hb}$ genes. The motifs are indicated by boldface in the gray boxes. 
pressed in roots, leaves, and stems, but its expression in nodules was barely detectable (Jacobsen-Lyon et al. 1995). In $L$. japonicus, two nonsym-Hb genes, $\mathrm{LjHb1}$ and $\mathrm{LjHb2}$, were expressed in several tissues of mature plants; in particular, $\mathrm{LjHbl}$ was enhanced in root nodules (Shimoda et al. 2005; Uchiumi et al. 2002). The expression of $A f H b l$ was also most significant in root nodules. Thus, $A f H b l$ showed a similar expression pattern to that of sym-Hb genes of legumes and the nonlegume P. andersonii $\mathrm{Hb}$ gene (Bogusz et al. 1988) but not the Casuarina nonsym-Hb gene (Jacobsen-Lyon et al. 1995).

\section{Induction of $\mathrm{AfHb1}$ expression}

under stress and chemical treatments.

We analyzed the expression of $\mathrm{AfHbl}$ under stress conditions by quantitative real-time RT-PCR (Fig. 5B). To detect the transcripts of $A f H b 1$, we used the primer pair AfHb1F1/AfHb1-R3. We exposed three-week-old plants for $48 \mathrm{~h}$ to hypoxia, cold stress $\left(4^{\circ} \mathrm{C}\right)$, or $3 \%$ sucrose (osmotic stress) and investigated the expression of $A f H b l . A f H b l$ was induced strongly under cold stress, approximately 12 times that of the control on average (Fig. 5B). On the other hand, no significant change in $A f H b l$ expression was found under hypoxia or osmotic stress (Fig. 5B). We also analyzed the induction of AfHbl in two-week-old seedlings treated with $\mathrm{KNO}_{3}, \mathrm{NaNO}_{2}$, or $S$-nitroso- $N$-acetyl-D,L-penicillamine (SNAP) as a NO donor. All chemicals induced $A f H b l$ expression strongly (Fig. 6). Furthermore, when whole plants were treated with each nitrogen compound mixed with a NO scavenger (carboxy-2-phenyl4,4,5,5-tetramethylimidazolinone-1-oxyl-3-oxide [c-PTIO]), the induction of $\mathrm{AfHbl}$ was repressed but not so much repressed in treatment with $\mathrm{KNO}_{3}$ (Fig. 6).

\section{Properties of recombinant AfHb1.}

We produced the recombinant protein of AfHb1 in E. coli cells and analyzed its properties and those of a sym-Hb of $L$. japonicus (LjLb3). The molecular masses were estimated to be 17,900 Da for recombinant AfHb1 and 15,500 Da for LjLb3 by sodium dodecyl sulfate-polyacrylamide gel electrophoresis

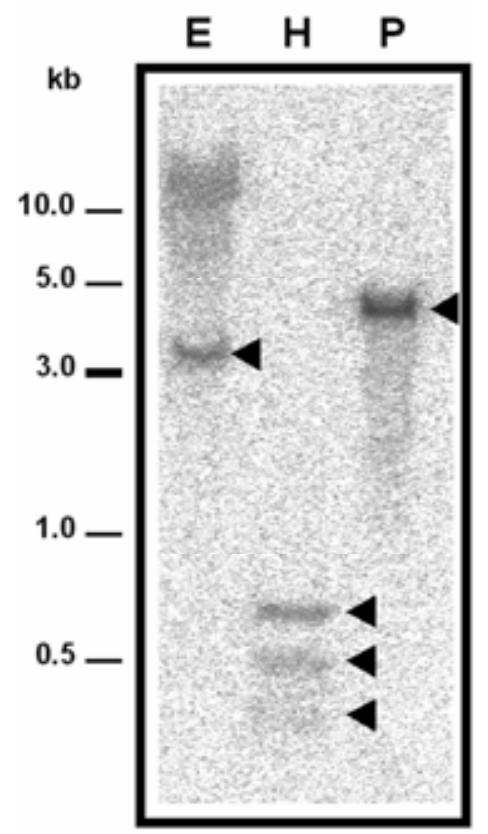

Fig. 3. Southern hybridization probing with partial fragments of $A f H b 1$. Genomic DNA of Alnus firma was digested with EcoRI (E), HindIII (H), and PstI (P). There are two HindIII sites and no EcoRI or PstI sites in the probe. The restriction fragments hybridized with the AfHbl probe are indicated by arrowheads.
(SDS-PAGE) (Fig. 7A). The molecular mass of AfHb1 is similar to those of other $\mathrm{Hb}$ proteins from actinorhizal plants: 18,300 Da from A. glutinosa (Suharjo and Tjepkema 1995), 17,500 Da from C. glauca (Fleming et al. 1987), and 16,200 Da from M. gale L. (Pathirana and Tjepkema 1995). The $C$. glauca nodule $\mathrm{Hb}$ is a class $2 \mathrm{Hb}$, the $A$. glutinosa $\mathrm{Hb}$ is, based on the current study, probably class 1 , and the grouping of the M. gale $\mathrm{Hb}$ is not known. We measured the binding activity of the recombinant $\mathrm{Hb}$ with NO. Oxygenated, purified, recombinant $\mathrm{Hb}$ exhibited characteristic spectra of $\mathrm{Hb}$ in the visible region (Fig. 7B); the position of two absorbance peaks of $\mathrm{AfHb} 1$ is nearly identical to those of rice (Oryza sativa) Hb1 (Goodman and Hargrove 2001). Treatment of oxygenated AfHb1 with NO produced a rapid collapse of spectra (Fig. $7 \mathrm{~B})$. On the other hand, the spectra of LjLb3 remained discernable after $30 \mathrm{~min}$ of incubation with NO (Fig. 7B). Timecourse measurement of spectra of NO-treated $\mathrm{Hb}$ revealed that AfHb1 could react more rapidly with NO than the sym-Hb could (Fig. 7B).

\section{Effects of NO on the nitrogenase activity of $A$. firma nodules.}

To investigate the effects on nitrogenase activity of A. firma, we measured acetylene reduction activity by nitrogenase in nodules of six-month-old plants inoculated with homogenate of A. firma nodules. Nitrogenase activity was strongly inhibited by the addition of $1 \mathrm{mM}$ SNAP as a NO donor, and the inhibition was clearly suppressed when c-PTIO (a NO scavenger) was added simultaneously with SNAP (Fig. 8). When the nodules were treated with c-PTIO alone, the acetylene reduction activity increased slightly. These results suggest that NO affects the nitrogenase activity of $A$. firma nodules in the same way as it affects the nitrogenase activity of soybean nodules (Trinchant and Rigaud 1982).

\section{DISCUSSION}

Plant $\mathrm{Hb}$ have been identified in various species of legumes, nonlegumes, and actinorhizal plants (e.g., C. glauca, M. gale, A. glutinosa), indicating that they exist widely in the plant kingdom.

We identified a gene encoding plant $\mathrm{Hb}$ in the cDNA library of A. firma nodules, which we named $A f H b l$. In the phylogenetic tree based on the amino acid sequences, AfHb1 is classified in a branch distant from sym-Hb of legumes, in the cluster of class 1 nonsym-Hb. Against our expectation, no clone for sym-Hb was identified in the library. We have made several vain attempts to isolate sym-Hb from A. firma by PCR with degenerate primers or by random sequencing of more than 200 cDNA clones from the nodule cDNA library. Our results suggest that sym-Hb may not occur in Alnus nodules. Suharjo and Tjepkema (1995) estimated that the average concentration of $\mathrm{Hb}$ in nodules of A. glutinosa was about $20 \mu \mathrm{M}$, lower than that in other actinorhizal plants and legumes. They also reported that nodule $\mathrm{Hb}$ in A. glutinosa does not play a role as an $\mathrm{O}_{2}$ transporter, as sym- $\mathrm{Hb}$ do, because the amount of $\mathrm{Hb}$ is too low to function as a transporter. But $\mathrm{Hb}$ concentrations in $A$. glutinosa nodules are certainly higher than in nodules of the actinorhizal plants Datisca glomerata, Coriaria myrtifolia, and Hippophae rhamnoides (Silvester et al. 1990). In Casuarina spp., $\mathrm{Hb}$ occur at high concentrations in nodules (Silvester et al. 1990), and Northern hybridization of both sym- and nonsym-Hb showed that a sym-Hb gene was expressed at a high level in nodules, and a nonsym-Hb gene was barely detectable (Jacobsen-Lyon et al. 1995).

The internal structures of Alnus and Casuarina nodules are different from each other. Casuarina spp. are unique among 


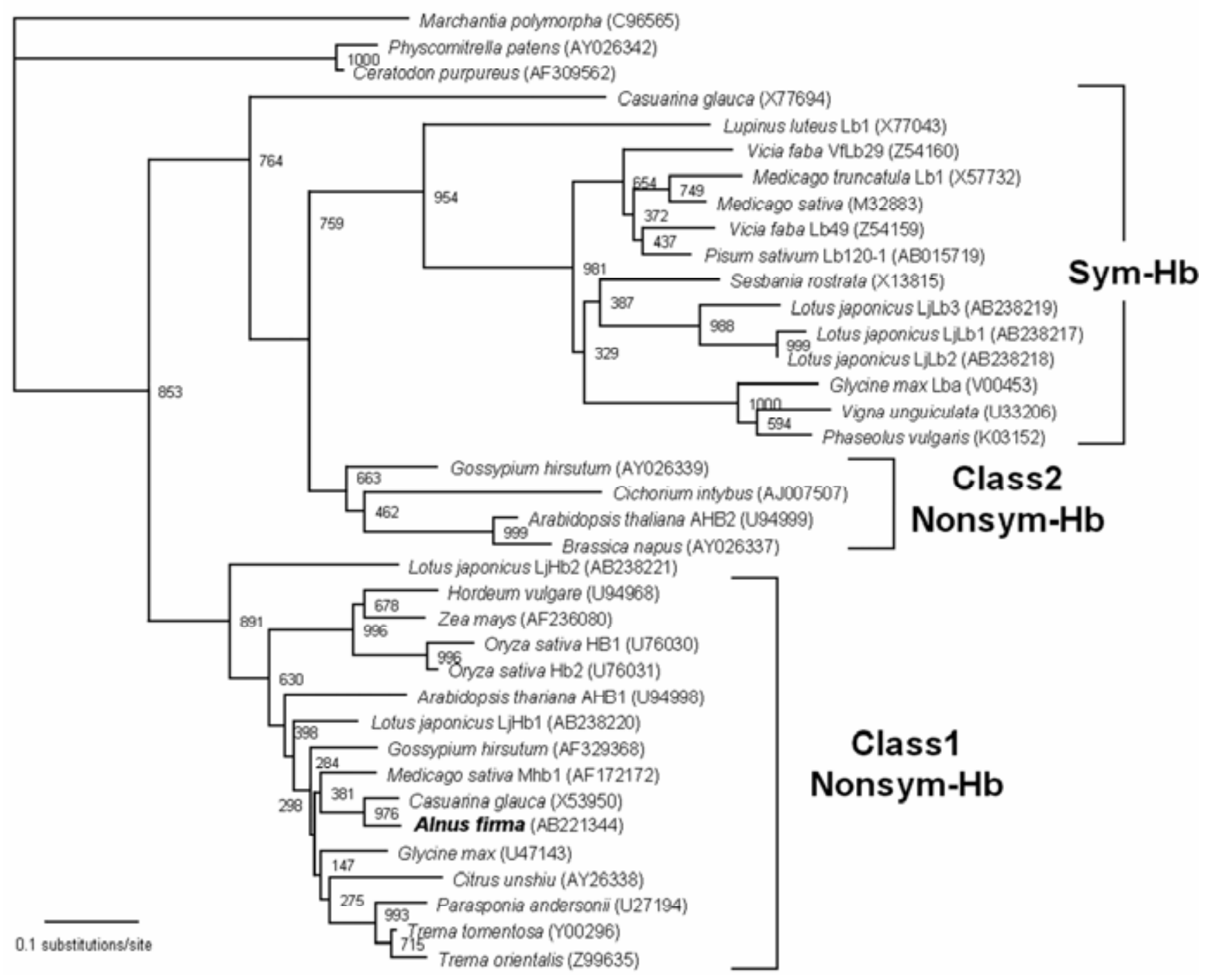

Fig. 4. Phylogenetic tree based on the amino acid sequences of plant hemoglobins. The tree was constructed by the neighbor-joining method in the ClustalW program. The numbers on the branches show bootstrap probabilities (as percentages) determined from 1,000 resamplings. The database accession numbers are indicated in parentheses after the plant names.

A

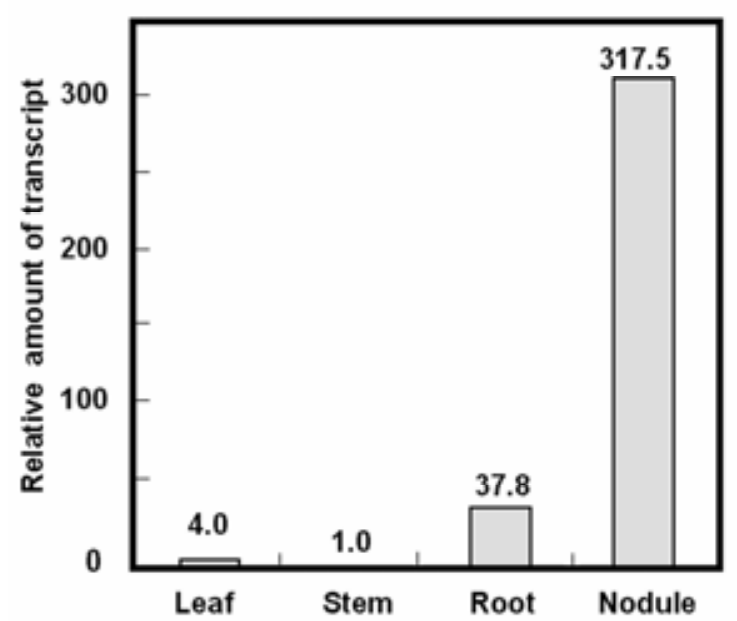

B

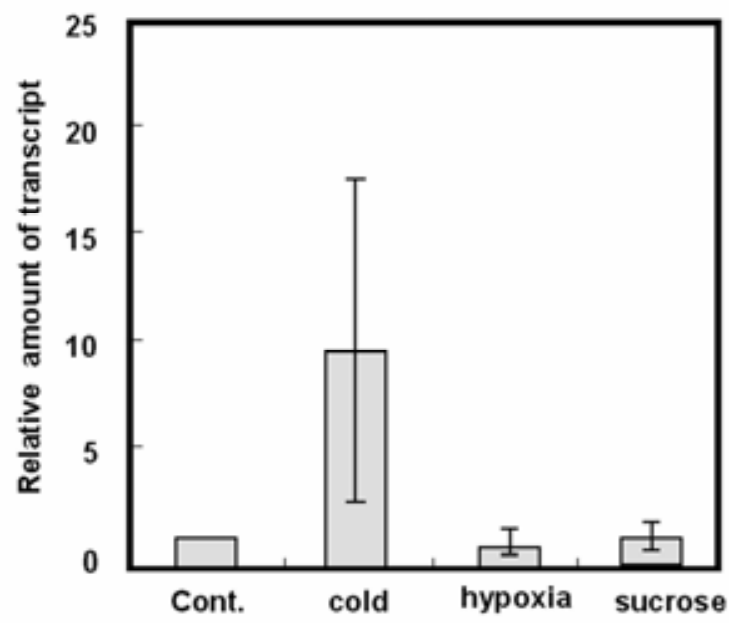

Fig. 5. Expression of $A f H b 1$ in different tissues and under stress conditions. A, Total RNA of each tissue was isolated from mature wild-grown plants. The amounts of transcripts in different tissues were estimated by quantitative reverse transcriptase-polymerase chain reaction. The numbers on the bars indicate the amounts relative to that in the stem. B, Total RNA was isolated from whole plants ( 3 weeks after germination) after 48 -h stress treatments. Values indicate the average of three independent experiments with standard deviation. Cont. $=$ untreated (control) plants. 
actinorhizal plants in that Frankia strains do not form vesicles within the nodules (Berg and McDowell 1987) but do form vesicles when grown in culture media (Murry et al. 1985). In A. firma nodules, spherical vesicles are formed (Fig. 1). Each vesicle is surrounded by a multilayered lipid envelope (Fig. $1 \mathrm{E})$, which presumably functions as an oxygen diffusion barrier (Parsons et al. 1987). Parsons and associates (1987) demonstrated that in culture media, vesicle envelopes thickened and the number of lipid layers increased in response to increasing oxygen concentration. The lack of vesicles in Casuarina nodules is attributed to low $\mathrm{O}_{2}$ tension created by abundant sym-Hb in nodules. Indeed, $\mathrm{O}_{2}$ tension is likely to be maintained at lower levels in Casuarina nodules than in Alnus nodules (Huss-Danell 1997). In nodules of A. incana, nitrogenase activity $\left(\mathrm{H}_{2}\right.$ evolution or acetylene reduction activity) was decreased at $\mathrm{O}_{2}$ tensions below and above ambient, indicating that the system to regulate $\mathrm{O}_{2}$ tension on the plant side was not flexible in Alnus-Frankia symbiosis as described by HussDanell (1997), Rosendahl and Huss-Danell (1988), and Lundquist (2000). At lower $\mathrm{O}_{2}$ tensions, $\mathrm{O}_{2}$ limits the energy generation for nitrogen fixation. At higher $\mathrm{O}_{2}$ tensions, more $\mathrm{O}_{2}$ enters the vesicles than the Frankia strains can consume, and thus, nitrogenase is inactivated. Our structural observation of numerous vesicles and our inability to identify sym-type $\mathrm{Hb}$ in A. firma nodules indicates that in the A. firma-Frankia symbiosis, the oxygen tension of the inner nodule might be controlled by layered vesicles instead of by sym-Hb.

Recent studies have reported the functional analyses of class 1 nonsym-Hb in transgenic plants or root cultures. These approaches were focused commonly on the relationships between $\mathrm{Hb}$ and $\mathrm{NO}$, one of the ligand molecules of $\mathrm{Hb}$. NO functions in the modulation of stress, hormonal, wounding, and defense responses, as well as in the regulation of cell death (Wendehenne et al. 2004). NO activates guanylate cyclase and cGMP, which induce the expression of defense genes, such as pathogen-related-1 and phenylalanine ammonia lyase genes (Durner et al. 1998; Klessig et al. 2000). NO is produced under hypoxia (Dordas et al. 2004) from nitrate or nitrite by nitrate reductase (Yamasaki and Sakihara 2000) and nonenzymatically by nitrite or nitrate reduction. Shimoda and associates

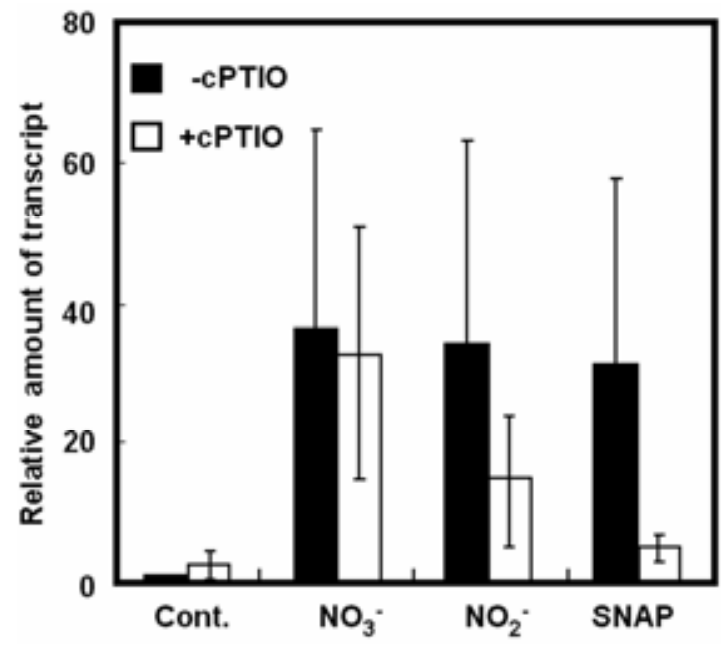

Fig. 6. Effects of treatments with nitrate $\left(\mathrm{NO}_{3}^{-}\right)$, nitrite $\left(\mathrm{NO}_{2}^{-}\right)$, and a $\mathrm{NO}$ donor ( $S$-nitroso- $N$-acetyl-D,L-penicillamine [SNAP]) with and without a NO scavenger (2 mM c-PTIO [carboxy-2-phenyl-4,4,5,5-tetramethylimidazolinone-1-oxyl-3-oxide]) on the expression of AfHb1. Total RNA was isolated from whole plants (two weeks after germination) treated with $\mathrm{NO}_{3}^{-}, \mathrm{NO}_{2}^{-}$, or SNAP in the dark. Values indicate the average of three independent experiments with standard error. Cont. = untreated (control) plants.
(2005) demonstrated that NO was generated in Lotus roots under both hypoxia and cold stress and the expression of $\mathrm{LjHbl}$ was increased simultaneously. Here, we demonstrated that the $A f H b l$ was induced strongly in NO-promoting conditions, such as cold stress, by a NO donor (SNAP) and by nitrogen compounds $\left(\mathrm{NO}_{2}^{-}, \mathrm{NO}_{3}^{-}\right)$, and that induction by SNAP and $\mathrm{NO}_{2}^{-}$was considerably repressed when the seedlings were simultaneously treated with a NO scavenger (c-PTIO) (Fig. 6). These results strongly support the view that $A f H b l$ expression corresponds to the cellular concentration of NO and might be involved in the modulation of NO levels in A. firma. Nitrate serves as a signal for regulating gene expression in nitrate assimilation (Crawford 1995), so AfHbl might be induced by nitrate itself. The induction of $A f H b l$ by nitrate should be investigated further.

We found enhanced expression of $A f H b l$ in root nodules (Fig. 5A). Additionally, the nodulin motifs (AAAGAT and CTCTT separated by six or seven nucleotides in the promoters of sym-Hb), which are critical for nodule-specific expression, are conserved in the promoter region of AfHbl (Fig. 2B). These results suggest that $A f H b l$ may have roles in root nodules that are involved in interactions with Frankia spp. In a Parasponia sp., a class 1 gene has been recruited for the symbiotic function (Bogusz et al. 1988; Landsmann et al. 1986). Furthermore, LjHb1, a nonsym-Hb of L. japonicus, was also expressed at high levels in root nodules and responded to microsymbionts (Uchiumi et al. 2002). LjHbl is supposed to be involved in interactions with microorganisms.

NO binds tightly to $\mathrm{Lb}$, forming nitrosylleghemoglobin complexes (NO-Lb) (Mathieu et al. 1998), and inhibits nitrogenase activity from soybean bacteroids (Trinchant and Rigaud 1982). Furthermore, NO is supposed to be a potent inhibitor of an $\mathrm{O}_{2}$ sensor (FixL) of symbiotic bacteroids and to decrease the efficiency of nitrogen fixation (Hérouart et al. 2002; Winkler et al. 1996). Here, we present the first report that NO inhibits nitrogenase activity of Frankia spp. In A. firma nodules, nitrogenase activity (acetylene reduction) was strongly inhibited by the addition of a NO donor, and the inhibition was clearly reduced when a NO scavenger was added simultaneously with the NO donor (Fig. 8). Cueto and associates (1996) reported NO synthase-like activity in nodules of Lupinus albus. It is conceivable that NO is generated and affects nitrogenase activity in A. firma root nodules because acetylene reduction activity was slightly increased under c-PTIO treatment (Fig. 8). In order to scavenge NO, which is a negative factor in nitrogen fixation, the expression of $\mathrm{AfHbl}$ might be enhanced in root nodules of $A$. firma.

We also tested in vitro binding of recombinant AfHb1 with $\mathrm{NO}$ and showed that AfHb1 exhibits higher affinity for NO than Lotus sym-Hb does (LjLb3) (Fig. 7B). NO reacts very rapidly with oxy-Hb to form nitrate and met-Hb (Dordas et al. 2004). Effective NO recycling gives plants advantages under some stress conditions by maintaining glycolysis (Dordas et al. 2004).

In summary, AfHb1 might contribute to stress adaptation and effective nitrogen fixation by binding to or recycling NO as a negative effecter. Our results will help researchers to understand the function of plant $\mathrm{Hb}$ and the details of AlnusFrankia symbiosis.

\section{MATERIALS AND METHODS}

\section{Plant materials.}

Seeds of $A$. firma were purchased from Terra-Tech (Tokyo, Japan), surface-sterilized with $0.5 \%$ sodium hypochlorite solution containing $0.1 \%$ Tween 20 and were germinated on agar plates at $25^{\circ} \mathrm{C}$ in the dark. After two weeks, the seedlings were 
transferred to Fåhraeus agar plates and were grown in a 16-hlight and 8-h-dark cycle at $25^{\circ} \mathrm{C}$ or were grown in a pot and then were inoculated with the homogenate of $A$. firma nodules. We also collected wild-grown $A$. firma to estimate the expression levels of $A f H b 1$ in nodules, roots, leaves, and stems.

\section{Observation of nodules}

by scanning and transmission electron microscopy.

After the root nodules were detached, scanning and transmission electron microscopy were carried out as described by Tani and associates (2003).

\section{Construction and screening}

of cDNA library of $A$. firma nodules.

Total RNA was extracted from root nodules by a modification of the cetyltrimethylammonium bromide method (Murray and
Thompson 1980). A cDNA library was constructed from $1 \mu \mathrm{g}$ of total RNA by using the SMART cDNA library construction kit according to the manufacturer's instructions (Clontech, Palo Alto, CA, U.S.A.). The cDNA library was stored at $-80^{\circ} \mathrm{C}$.

DNA probes for sym- and nonsym-Hb genes were obtained by PCR using LjLb3 (sym-) and LjHbl (nonsym-) Hb clones of Lotus japonicus as templates. The sequences of primers for amplification were as follows: 5'-CAATGTTCCTATTGTCCA CT-3' and 5'-CTGCCAAACAAAGAATAGCA-3' for $L j L b 3$

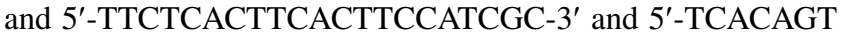
GACTTTTCCAGCC-3' for $L j H b l$. The PCR products were labeled with $\alpha{ }^{32} \mathrm{P}-\mathrm{dCTP}$ by using the Multiprime DNA labeling system (Amersham, Little Chalfont, Buckinghamshire, U.K.) and were used as probes.

To identify the Alnus Hb genes, we carried out two-step plaque hybridization. For the first screening, the phage lysate
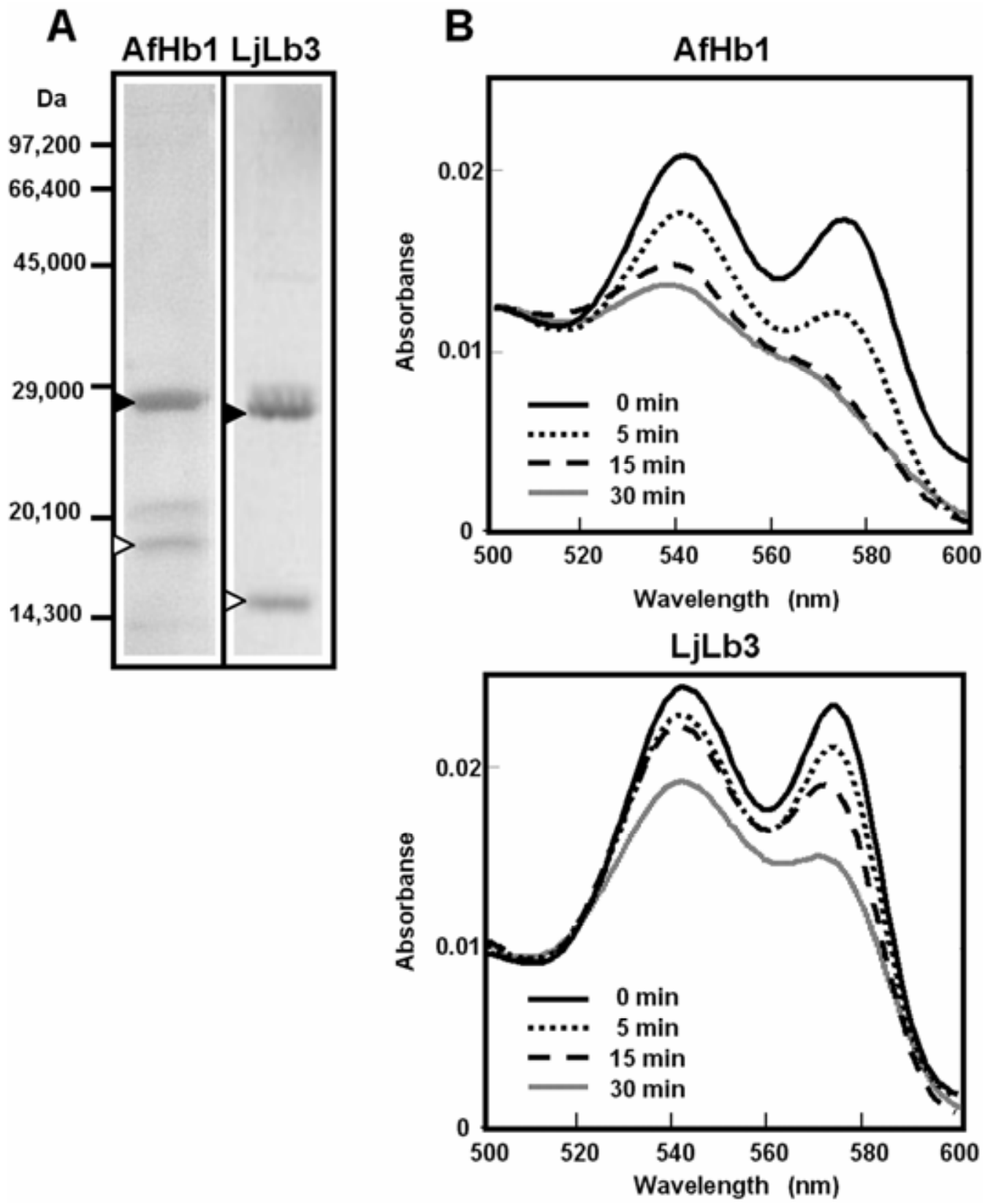

Fig. 7. Sodium dodecyl sulfate-polyacrylamide gel electrophoresis (SDS-PAGE) and spectra of recombinant hemoglobins (Hb). A, After GST (glutathione $S$ transferase) was digested by thrombin protease, recombinant $\mathrm{Hb}$ proteins (AfHb1 and LjLb3) were separated by SDS-PAGE in 12\% wt/vol polyacrylamide gel. GST proteins are indicated by black arrowheads, and each recombinant $\mathrm{Hb}$ protein by white arrowheads. B, Absorption spectra were recorded 0 (solid black), 5 (dotted), 15 (dashed), and $30 \mathrm{~min}$ (gray) after the addition of $5 \mu \mathrm{M}$ NO donor ( $S$-nitroso- $N$-acetyl-D,L-penicillamine) to $5 \mu \mathrm{M}$ Hb solutions. 
of the cDNA library was plated at $5 \times 10^{4}$ and $5 \times 10^{3}$ plaques per plate. The plaques were transferred to nylon filters (Immobilon-Ny'; Millipore, Billerica, MA, U.S.A.). Hybridization was carried out as described in Uchiumi and associates (2002). Each positive phage lysate was plated again to pick up single clones and was then screened again under the same conditions. $\lambda$-Phage DNAs were transverted into plasmids (pTriplEx2) on individual positive plaques of the second-screening plates, using a SMART cDNA library construction kit.

\section{DNA sequencing and phylogenetic analysis.}

Sequencing was carried out with a BigDye terminator v3.0 cycle sequencing ready reaction kit (Applied Biosystems, Foster City, CA, U.S.A.), and the sequences were decided with the use of an ABI PRISM 310 genetic analyzer (Applied Biosystems). Sequence data were analyzed with DNASIS software (Hitachi Software Engineering, Tokyo). A phylogenetic tree was constructed (Fig. 4), comparing deduced amino acid sequences with known plant $\mathrm{Hb}$ genes, by using the neighborjoining method in the ClustalW program.

\section{PCR and TAIL-PCR.}

For amplification of sym-Hb of A. firma, ExTaq (TaKaRa, Shiga, Japan) and the degenerate primers were used with genomic DNA or cDNA of $A$. firma root nodules as templates: symF-a, 5'-TTTBACWGMDMRRCAAGADGCT-3'; symF-b, 5'-MRRCAAGADGCTYTRKTD-3'; symF-c, 5'-AYAGYVTT BKKYTCTWYRC-3'; symR-a, 5'-AGYARDGCTYCTTTMA YCAC-C-3'; symR-b, 5'-CDCRAAATGDGGRTCA-RYRA-3'; and symR-c, 5'-AAWABYWBTKCAG-CATGGSC-3'.

To determine the $5^{\prime}$ upstream region of $A f H b 1$, TAIL-PCR was performed using the following primers: AfHbR, 5'-ACTT TGCCGGCTTTCCG-3'; AfHbR1, 5'-GGCTTCATTGCATTC CATGAC-3'; and AfHbR2, 5'-CACCACAGCTTCTTGCTCT TC-3'. TAIL-PCR was as by Liu and associates (1995) (Fig. 2B).

\section{Southern hybridization.}

The genomic DNA of $A$. firma was purified by $\mathrm{CsCl}-\mathrm{EtBr}$ dye buoyant-density gradient centrifugation and was digested

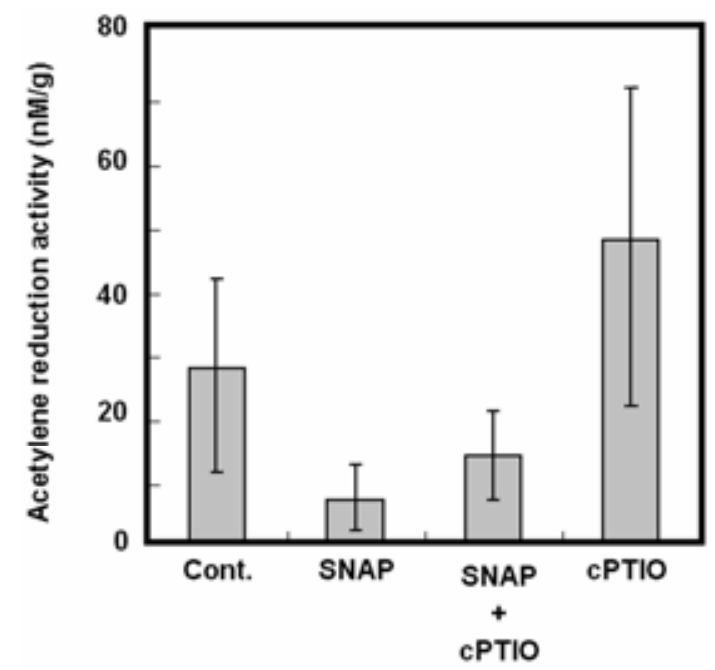

Fig. 8. Effects of NO donor ( $S$-nitroso- $N$-acetyl-D,L-penicillamine [SNAP]) and NO scavenger carboxy-2-phenyl-4,4,5,5-tetramethylimidazolinone-1-oxyl-3-oxide [c-PTIO]) on nitrogenase activity. Young plants of Alnus firma were inoculated with nodule homogenates of wild-grown $A$. firma. After cultivation for six months, nodules were harvested and treated for 30 min with $1 \mathrm{mM}$ SNAP alone, SNAP mixed with $2 \mathrm{mM} \mathrm{c}-\mathrm{PTIO}$, or c-PTIO alone. The values indicate the average of three independent experiments with standard error. Cont. $=$ untreated (control) plants. with EcoRI, HindIII, and PstI. The digests (approximately 4 $\mu \mathrm{g})$ were separated in $0.7 \%$ agarose gel and then were transferred to a nylon filter. DNA probes for $A f H b l$ and sym-Hb gene of $C$. glauca were obtained by PCR using pAfHb1 and genomic DNA of $C$. glauca as templates, respectively. The sequences of each primer fragment used for amplification were as follows: AfHb-FF1, 5'-CACAGAAGAGCAAGAAGCTG3'; AfHb-RR, 5'-CCTTGATCAGGAAAGAG-3'; CgSymhbF1, 5'-CAGAGAGGCAAGAAG-CTTTG-3'; and CgSymhbR2, 5'-GATGAATTGAACCCAAGCGC-3'. Hybridization and labeling of the PCR products were performed as for screening of the cDNA library.

\section{Stress treatments of plants.}

Three-week-old seedlings were exposed to hypoxia, cold stress $\left(4^{\circ} \mathrm{C}\right)$, or osmotic stress $(3 \%$ sucrose) for $48 \mathrm{~h}$ in the dark, as described in Shimoda and associates (2005). Control plants were incubated at $25^{\circ} \mathrm{C}$ for $48 \mathrm{~h}$ in the dark. Total RNA was isolated by using a Plant total RNA extraction miniprep system (Viogene, Sunnyvale, CA, U.S.A.).

\section{Treatment of plants}

with NO donor and nitrogen compounds.

Two-week-old seedlings were put between papers moistened with distilled water containing $5 \mathrm{mM} \mathrm{KNO}_{3}$ or $5 \mathrm{mM} \mathrm{NaNO}$ for $24 \mathrm{~h}$ or $1 \mathrm{mM} \mathrm{SNAP}$ as a NO donor for $3 \mathrm{~h}$ at $25^{\circ} \mathrm{C}$ in the dark. Other seedlings were treated simultaneously with the $\mathrm{N}$ compounds or SNAP and $2 \mathrm{mM}$ c-PTIO as a NO scavenger.

\section{Analysis of expression of the $\mathrm{Hb}$ gene.}

The expression of the $H b$ gene of $A$. firma was measured by quantitative RT-PCR in a 7700 sequence detection system (Applied Biosystems). DNase I-treated total RNA (50 ng) was used as a template. Each $25 \mu$ lof real-time RT-PCR reaction mixture contained $12.5 \mu \mathrm{l}$ of SYBR Green PCR master mix (Applied Biosystems), $0.125 \mu \mathrm{l}$ of RNase inhibitor (40 $\mathrm{Ul}^{-1}$; TaKaRa), $0.125 \mu \mathrm{l}$ of Superscript II-RT (200 U $\mathrm{Ul}^{-1}$; Invitrogen), and $1 \mu \mathrm{l}$ of each primer pair $(5 \mu \mathrm{M})$. PCR was carried out in 40 cycles of $95^{\circ} \mathrm{C}$ for $15 \mathrm{~s}$ and $60^{\circ} \mathrm{C}$ for $1 \mathrm{~min}$. The sequences of primers for real-time RT-PCR were as follows: AfHb-1F1, 5'-GCTGCTATCAAATCTGCAAT-3' and AfHb-1R3, 5'-GG GGGGCTGTGATTTTAG-3' for AfHbl. The amount of $18 \mathrm{~S}$ rRNA transcripts was used for normalization. The primers for detection of 18S rRNA were 5'-CCTAGTAAGCGCGAGTCA TC-3' and 5'-CATTCAATCGGTAGGAGCGA-3'.

\section{Production of $A$. firma recombinant $\mathrm{Hb}$.}

The complete cDNAs of $A f H b 1$ and $L j L b 3$ were obtained by RT-PCR using gene-specific primer pairs containing an EcoRI restriction site and Pyrobest DNA polymerase (TaKaRa). The sequences used were as follows: for $A f H b 1,5^{\prime}$-GCGGAATTC GATGAACACCTTGGAAGGAAG-3' and 5'-CGCGAATTCC TAAGAAGAAGGCTTCATTGC-3'; for $L j L b 3,5^{\prime}$-GCGGAAT TCCATGGGTTTCACTGCGCAGCA-3' and 5'-CGCGGAAT TCTTAACCCATTGCCTTCTTAA-3'. The PCR products were digested with EcoRI, were ligated into the EcoRI site of the GST (glutathione $S$-transferase)-linker region of the pGEX-4T3 expression vector (Pharmacia), and then, were transformed into $E$. coli $\mathrm{DH} 5 \alpha$. The transformant was cultured overnight in $100 \mathrm{ml}$ of Luria-Bertani (LB) medium containing $100 \mu \mathrm{g}$ of carbenicillin per milliliter, with shaking at $37^{\circ} \mathrm{C}$. More LB medium containing carbenicillin was inoculated with the overnight culture and was incubated at $25^{\circ} \mathrm{C}$ for $1.5 \mathrm{~h}$. Then IPTG (isopropyl $\beta$-D-thiogalactopyranoside, final concentration 1 $\mathrm{mM}$ ) was added. After $24 \mathrm{~h}$ at $25^{\circ} \mathrm{C}$, the induced cells were centrifuged and resuspended in $20 \mathrm{ml}$ of cold PBS buffer (16 $\mathrm{mM} \mathrm{Na}_{2} \mathrm{HPO}_{4}, 4 \mathrm{mM} \mathrm{NaH} \mathrm{PO}_{4}, 150 \mathrm{mM} \mathrm{NaCl}, \mathrm{pH}$ 8.0). Lyso- 
zyme $(1 \mathrm{mg} / \mathrm{ml})$ was added to burst the cells. After $30 \mathrm{~min}$ of incubation on ice, cells were sonicated and centrifuged, and supernatants were collected. To purify Hb proteins, we mixed the supernatant with Sepharose 4B beads and removed the GST tag by digestion with thrombin protease according to the manufacturer's instructions (Pharmacia). $\mathrm{Hb}$ was then either immediately used for analysis or stored at $-80^{\circ} \mathrm{C}$ until needed.

Protein concentration was measured by the method of Bradford (1976), using prepared reagent (Bio-Rad, Hercules, CA, U.S.A.) and bovine serum albumin as a standard. Spectra were recorded in an Ultrospec 3300 Pro UV/Vis spectrophotometer (Amersham).

Each purified recombinant $\mathrm{Hb}$ was separated by SDS-PAGE in $12 \%$ (wt/vol) polyacrylamide.

\section{Spectrophotometric analysis of $\mathbf{H b}$.}

Spectrophotometric analysis used $5 \mu \mathrm{M}$ recombinant $\mathrm{Hb}$ in an Ultrospec 3300 Pro UV/Vis spectrophotometer (Amersham) at wavelength range of 400 to $600 \mathrm{~nm}$. Purified recombinant $\mathrm{Hb}$ in their oxygenated state $\left[\mathrm{Hb}\left(\mathrm{Fe}^{2+}\right) \mathrm{O}_{2}\right]$ were dissolved in $50 \mathrm{mM}$ Tris $\cdot \mathrm{HCl}$, and then, $5 \mu \mathrm{M}$ SNAP (final concentration) was added and spectra were recorded at 5, 15, and 30 min after SNAP addition. The spectroscopic analysis followed the method of Perazzolli and associates (2004).

\section{Measurement of acetylene reducing activity.}

Six months after inoculation of the homogenate of $A$. firma nodules, nodules were harvested and placed for $30 \mathrm{~min}$ on filter paper soaked with $1 \mathrm{mM}$ SNAP alone, SNAP mixed with 2 $\mathrm{mM}$ carboxy-PTIO, or carboxy-PTIO alone.

Nodule samples in vials containing $20 \%$ acetylene in air were then incubated in the dark for $1 \mathrm{~h}$ at $25^{\circ} \mathrm{C}$. After incubation, the gas phase was analyzed by gas chromatography (GC3A, Shimadzu, Kyoto, Japan). Nitrogenase activity was calculated from production of ethylene per gram of nodules and is expressed as acetylene reduction activity.

\section{ACKNOWLEDGMENTS}

This work was supported in part by Special Coordination Funds for Promoting Science and Technology from the Ministry of Education, Culture, Sports, Science and Technology in Japan.

\section{LITERATURE CITED}

Andersson, C. R., Jensen, E. O., Llewellyn, D. J., Dennis, E. S., and Peacock, W. J. 1996. A new hemoglobin gene from soybean: A role for hemoglobin in all plants. Proc. Natl. Acad. Sci. U.S.A. 93:5682-5687.

Appleby, C. A. 1992. The origin and function of haemoglobin in plants. Sci. Prog. 76:365-398.

Arrendondo-Peter, R., Hargrove, M. S., Sarath, G., Moran, J. F., Lohrman, J., Olson, J. S., and Klucas, R. V. 1997. Rice hemoglobins. Plant Physiol. 115:1259-1266.

Berg, R. H., and McDowell, L. 1987. Endophyte differentiation in Casuarina actinorhizae. Protoplasma. 136:104-117.

Bogusz, D., Appleby, C. A., Landsmann, J., Dennis, E.S., Trinick, M. J., and Peacock, W. J. 1988. Functioning haemoglobin genes in non-nodulating plants. Nature 331:178-180.

Bradford, M. M. 1976. A rapid and sensitive method for the quantitation of microgram quantities of protein utilizing the principle of protein-dye binding. Anal. Biochem. 72:248-254.

Crawford, N. M. 1995. Nitrate: Nutrient and signal for plant growth. Plant Cell 7:859-868.

Cueto, M., Hernández-Perera, O., Martín, R., Bentura, M. L., Rodrigo, J., Lamas, S., and Golvano, M., P. 1996. Presence of nitric oxide synthase activity in roots and nodules of Lupinus albus. FEBS (Fed. Eur. Biochem. Soc.) Lett. 398:159-164.

Dordas, C., Hasinoff, B. B., Igamberdiev, A. U., Manac'h, N., Rivoal, J., and Hill, R. D. 2003. Expression of a stress-induced hemoglobin affects NO levels produced by alfalfa root cultures under hypoxic stress. Plant J. 35:763-770.
Dordas, C., Hasinoff, B. B., Rivoal, J., and Hill, R. D. 2004. Class-1 hemoglobins, nitrate and NO levels in anoxic maize cell-suspension cultures. Planta 219:66-72.

Duff, S. M. G., Wittenberg, J. B., and Hill, R. D. 1997. Expression, purification, and properties of recombinant barley (Hordeum sp.) hemoglobin. J. Biol. Chem. 272:16746-16752.

Durner, J., Wendehenne, D., and Klessig, D. F. 1998. Defense gene induction tobacco by nitric oxide, cyclic GMP, and cyclic ADP-ribose. Proc. Natl. Acad. Sci. U.S.A. 95:10328-10333.

Fleming, A. I., Wittenberg, J. B., Wittenberg, B. A., Dudmanc, W. F., and Appleby, C. A. 1987. The purification, characterization and ligandbinding kinetics of hemoglobins from root nodules of the non-leguminous Casuarina glauca-Frankia symbiosis. Biochim. Biophys. Acta 911:209-220.

Goetting-Minesky, M. P., and Mullin, B. C. 1994. Differential gene expression in an actinorhizal symbiosis: Evidence for a nodule-specific cysteine proteinase. Proc. Natl. Acad. Sci. U.S.A. 91:9891-9895.

Goodman, M. D., and Hargrove, M. S. 2001. Quaternary structure of rice nonsymbiotic hemoglobin. J. Biol. Chem. 276:6834-6839.

Guldner, E., Godelle, B., and Galtier, N. 2004. Molecular adaptation in plant hemoglobin, a duplicated gene involved in plant-bacteria symbiosis. J. Mol. Evol. 59:416-425.

Hérouart, D., Baudouin, E., Frendo, P., Harrison, J., Santos, R., Jamet, A., Van de Sype, G., Touati, D., and Puppo, A. 2002. Reactive oxygen species, nitric oxide and glutathione: A key role in the establishment of the legume-Rhizobium symbiosis? Plant Physiol. Biochem. 40:619-624.

Hunt, P. W., Watts, R. A., Trevaskis, B., Llewelyn, D. J., Burnell, J., Dennis, E. S., and Peacock, W. J. 2001. Expression and evolution of functionally distinct haemoglobin genes in plants. Plant Mol. Biol. 47:677-692.

Hunt, P. W., Klok, E. J., Trevaskis, B., Watts, R. A., Ellis, M. H., Peacock, W. J., and Dennis, E. S. 2002. Increased level of hemoglobin 1 enhances survival of hypoxic stress and promotes early growth in Arabidopsis thaliana. Proc. Natl. Acad. Sci. U.S.A. 99:17197-17202.

Huss-Danell, K. 1997. Actinorhizal symbiosis and their $\mathrm{N}_{2}$ fixation. New Phytol. 136:375-405.

Jacobsen-Lyon, K., Jensen, E. Ø., Jørgensen, J.-E., Marcker, K. A., Peacock, W. J., and Dennis, E. S. 1995. Symbiotic and nonsymbiotic hemoglobin genes of Casuarina glauca. Plant Cell 7:213-223.

Jiménez-Zurdo, J. I., Frugier, F., Crespi, M. D., and Kondorosi, A. 2000. Expression profiles of 22 novel molecular markers for organogenetic pathways acting in alfalfa nodule development. Mol. Plant-Microbe Interact. 13:96-106.

Klessig, D. F., Durner, J., Noad, R., Navarre, D. A., Wendehenne, D., Kumar, D., Zhou, J. M., Shah, J., Zhang, S., Kachroo, P., Trifa, Y., Pontier, D., Lam, E., and Silva, H. 2000. Nitric oxide and salicylic acid signaling in plant defense. Proc. Natl. Acad. Sci. U.S.A. 97:8849-8855.

Landsmann, J., Dennis, E. S., Higgins, T. J., Appleby, C. A., Kortt, A. A. and Peacock, W. J. 1986. Common evolutionary origin of legume and non-legume plant haemoglobins. Nature 324:166-168.

Liu, Y.-G., and Whittier, R. F. 1995. Thermal asymmetric interlaced PCR: Automatable amplification and sequencing of insert end fragments from P1 and YAC clones for chromosome walking. Genomics 25:674-681.

Lundquist, P.-O. 2000. Nitrogenase activity in Alnus incana root nodules. Responses to $\mathrm{O}_{2}$ and short-term $\mathrm{N}_{2}$ deprivation. Plant Physiol. 122:553561.

Mathesius, U., Charon, C., Rolfe, B. G., Kondorosi, A., and Crespi, M. 2000. Temporal and spatial order of events during the induction of cortical cell divisions in white clover by Rhizobium leguminosarum bv. trifolii inoculation or localized cytokinin addition. Mol. Plant-Microbe Interact. 13:617-628.

Mathieu, C., Moreau, S., Frendo, P., Puppo, A., and Davies, M. J. 1998. Direct detection of radicals in intact soybean nodules: Presence of nitric oxide-leghemoglobin complexes. Free Radical Biol. Med. 24:12421249.

Murray, G. C., and Thompson, W. F. 1980. Rapid isolation of high molecular weight DNA. Nucleic Acid. Res. 8:4321-4325.

Murry, M. A., Zhang Z., and Torrey, J. G. 1985. Effect of $\mathrm{O}_{2}$ on vesicle formation, acetylene reduction, and $\mathrm{O}_{2}$-uptake kinetics in Frankia sp. HEPCcI3 isolated from Casuarina cunninghamiana. Can. J. Microbiol. 31:804-809.

Parsons, R., Silvester, W. B., Harris, S., Gruijters, W. T. M., and Bullivant, S. 1987. Frankia vesicles provide inducible and absolute oxygen protection for nitrogenase. Plant Physiol. 83:728-731.

Pathirana, S. M., and Tjepkema, J. D. 1995. Purification of hemoglobin from the actinorhizal root nodules of Myrica gale L. Plant Physiol. 107:827-831.

Perazzolli, M., Dominici, P., Romero-Puertas, M. C., Zago, E., Zeier, J., Sonoda, M., Lamb, C., and Delledonne, M. 2004. Arabidopsis nonsymbiotic hemoglobin AHb1 modulates nitric oxide bioactivity. Plant Cell $16: 2785-2794$. 
Ribeiro, A., Akkermans, A. D. L., van Kammen, A., Bisseling, T., and Pawlowski, K. 1995. A nodule-specific gene encoding a subtilisin-like protease is expressed in early stages of actinorhizal nodule development. Plant Cell 7:785-794.

Rosendahl, L., and Huss-Danell, K. 1988. Effects of elevated oxygen tensions on acetylene reduction in Alnus incana-Frankia symbioses. Physiol. Plant. 74:89-94.

Seregélyes, C., Mustárdy, L., Ayaydin, F., Sass, L., Kovács, L., Endre, G., Lukács, N., Kovács, I., Vass, I., Kiss, G. B., Horváth, G. V., and Dudits, D. 2000. Nuclear localization of a hypoxia-inducible novel non-symbiotic hemoglobin in cultured alfalfa cells. FEBS (Fed. Eur. Biochem. Soc.) Lett. 482:125-130.

Shimoda, Y., Nagata, M., Suzuki, A., Abe, M., Sato, S., Kato, T., Tabata, S., Higashi, S., and Uchiumi, T. 2005. Symbiotic rhizobium and nitric oxide induce gene expression of non-symbiotic hemoglobin in Lotus japonicus. Plant Cell Physiol. 46:99-107.

Silvester W. B, Harris, S. L., and Tjepkema, J. D. 1990. Oxygen regulation and hemoglobin. Pages 157-174 in: The Biology of Frankia and Actinorhizal Plants. C. R. Schwintzer and J. D. Tjepkema, eds. Academic Press, San Diego, CA. U.S.A.

Suharjo, U. K. J., and Tjepkema, J. D. 1995. Occurrence of hemoglobin in the nitrogen-fixing root nodules of Alnus glutinosa. Physiol. Plantarum 95:247-252.

Tani, C., Sasakawa, H., Takenouchi, K., Abe, M., Uchiumi, T., Suzuki, A., and Higashi, S. 2003. Isolation of endophytic Frankia from root nodules of Casuarina equisetifolia and infectivity of the isolate to host plants. Soil Sci. Plant Nutr. 49:137-142.

Taylor, E. R., Nie, X. Z., MacGregor, A. W., and Hill, R. D. 1994. A cereal hemoglobin gene is expressed in seed and root tissues under anaerobic conditions. Plant Mol. Biol. 24:853-862.
Trevaskis, B., Watts, R. A., Andersson, C. R., Llewellyn, D. J., Hargrove, M. S., Olson, J. S., Dennis, E. S., and Peacock, W, J. 1997. Two hemoglobin genes in Arabidopsis thaliana: The evolutionary origins of leghemoglobins. Proc. Natl. Acad. Sci. U.S.A. 94:12230-12234.

Trinchant, J.-C., and Rigaud, J. 1982. Nitrite and nitric oxide as inhibitors of nitrogenase from soybean bacteroids. Appl. Env. Microbiol. 44:1385-1388

Uchiumi, T., Shimoda, Y., Tsuruta, T., Mukoyoshi, Y., Suzuki, A., Senoo, K., Sato, S., Kato, T., Tabata, S., Higashi, S., and Abe, M. 2002. Expression of symbiotic and nonsymbiotic globin genes responding to microsymbionts on Lotus japonicus. Plant Cell Physiol. 43:1351-1358.

Vieweg, M. F., Hohnjec, N., and Küster, H. 2005. Two genes encoding different truncated hemoglobins are regulated during root nodule and arbuscular mycorrhiza symbioses of Medicago truncatula. Planta 220:757-766.

Watts, R. A., Hunt, P. W., Hvitved, A. N., Hargrove, M. S., Peacock, W. J., and Dennis, E. S. 2001. A hemoglobin from plants homologous to truncated hemoglobins of microorganisms. Proc. Natl. Acad. Sci. U.S.A. 98:10119-10124.

Wendehenne, D., Durner, J., and Klessig, D. F. 2004. Nitric oxide: A new player in plant signaling and defence responses. Curr. Opin. Plant Biol. 7:449-455

Winkler, W. C., Gonzalez, G., Wittenberg, J. B., Hille, R., Dakappagari, N., Jacob, A., Gonzalez, L. A., and Gilles-Gonzalez, M. A. 1996. Nonsteric factors dominate binding of nitric oxide, azide, imidazole, cyanide, and fluoride to the Rhizobial heme-based oxygen sensor FixL. Chem. Biol. 3:841-850.

Yamasaki, H., and Sakihama, Y. 2000. Simultaneous production of nitric oxide and peroxynitrite by plant nitrate reductase: In vitro evidence for the NR-dependent formation of active nitrogen species. FEBS (Fed. Eur. Biochem. Soc.) Lett. 468:89-92. 